\title{
Correction: Rezension zu: Wolfgang Ballwieser/Dirk Hachmeister (Hrsg.): Digitalisierung und Unternehmensbewertung - Neue Objekte, Prozesse, Parametergewinnung, Schäffer-Poeschel, Stuttgart 2019
}

\author{
Andreas Haaker
}

Online publiziert: 4 . November 2021

(C) Der/die Autor(en) 2021

\section{Correction:}

Schmalenbach J Bus Res 2020

https://doi.org/10.1007/s41471-020-00082-5

Der Artikel Rezension zu: Wolfgang Ballwieser/Dirk Hachmeister (Hrsg.): Digitalisierung und Unternehmensbewertung - Neue Objekte, Prozesse, Parametergewinnung, Schäffer-Poeschel, Stuttgart 2019 von Andreas Haaker wurde ursprünglich Online First ohne „Open Access“ auf der Internetplattform des Verlags publiziert. Nach der Veröffentlichung in Band 72 Heft 3 pp. 397-400 hatten sich der Autor für eine „Open Access“-Veröffentlichung entschieden. Das Urheberrecht des Artikels wurde deshalb in (C) Der/die Autor(en) 2021 geändert. Dieser Artikel ist jetzt unter der Creative Commons Namensnennung 4.0 International Lizenz veröffentlicht, welche die Nutzung, Vervielfältigung, Bearbeitung, Verbreitung und Wiedergabe in jeglichem Medium und Format erlaubt, sofern Sie den/die ursprünglichen Autor(en) und die Quelle ordnungsgemäß nennen, einen Link zur Creative Commons Lizenz beifügen und angeben, ob Änderungen vorgenommen wurden.

Die in diesem Artikel enthaltenen Bilder und sonstiges Drittmaterial unterliegen ebenfalls der genannten Creative Commons Lizenz, sofern sich aus der Abbildungslegende nichts anderes ergibt. Sofern das betreffende Material nicht unter der genannten Creative Commons Lizenz steht und die betreffende Handlung nicht nach gesetzlichen Vorschriften erlaubt ist, ist für die oben aufgeführten Weiterverwendungen des Materials die Einwilligung des jeweiligen Rechteinhabers einzuholen.

Die Online-Version des Originalartikels ist unter https://doi.org/10.1007/s41471-020-00082-5 zu finden.

Andreas Haaker $(\bowtie)$

Freie Universität Berlin sowie DGRV - Deutscher Genossenschafts- und Raiffeisenverband e. V., Linkstraße 12, 10785 Berlin, Deutschland

E-Mail: haaker@dgrv.de 
Open Access Dieser Artikel wird unter der Creative Commons Namensnennung 4.0 International Lizenz veröffentlicht, welche die Nutzung, Vervielfältigung, Bearbeitung, Verbreitung und Wiedergabe in jeglichem Medium und Format erlaubt, sofern Sie den/die ursprünglichen Autor(en) und die Quelle ordnungsgemäß nennen, einen Link zur Creative Commons Lizenz beifügen und angeben, ob Änderungen vorgenommen wurden.

Die in diesem Artikel enthaltenen Bilder und sonstiges Drittmaterial unterliegen ebenfalls der genannten Creative Commons Lizenz, sofern sich aus der Abbildungslegende nichts anderes ergibt. Sofern das betreffende Material nicht unter der genannten Creative Commons Lizenz steht und die betreffende Handlung nicht nach gesetzlichen Vorschriften erlaubt ist, ist für die oben aufgeführten Weiterverwendungen des Materials die Einwilligung des jeweiligen Rechteinhabers einzuholen.

Weitere Details zur Lizenz entnehmen Sie bitte der Lizenzinformation auf http://creativecommons.org/ licenses/by/4.0/deed.de. 